\begin{tabular}{|c|c|}
\hline Title & Future Changes in Monthly Extreme Precipitation in Japan U sing Large Ensemble Regional Climate Simulations \\
\hline Author(s) & Hatsuzuka, Dai suke; Sato, T omonori \\
\hline Citation & $\begin{array}{l}\text { Journal of hydrometeorology, 20(3), 563-574 } \\
\text { https://doi.org/10.1175/JHM-D-18-0095.1 }\end{array}$ \\
\hline Issue Date & $2019-03$ \\
\hline Doc URL & http:/hdl.handle.net/2115/75503 \\
\hline Rights & $\begin{array}{l}\text { () Copyright 2019-03-22 A merican Meteorological Society (A MS). Permission to use figures, tables, and brief excerpts } \\
\text { from this work in scientific and educational works is hereby granted provided that the source is acknowledged. A ny use } \\
\text { of material in this work that is determined to be " fair use" under Section } 107 \text { of the U.S. Copyright Act or that } \\
\text { satisfies the conditions specified in Section } 108 \text { of the U.S. Copyright Act (17 USC } \S 108 \text { ) does not require the } \\
\text { A MS' s permission. Republication, sy stematic reproduction, posting in electronic form, such as on a web site or in a } \\
\text { searchable database, or other uses of this material, except as exempted by the above statement, requires written } \\
\text { permission or a license from the A MS. AII A MS journals and monograph publications are registered with the Copyright } \\
\text { Clearance Center (http:/Www.copyright.com). Questions about permission to use material s for which A MS holds the } \\
\text { copyright can al so be directed to permissions@ ametsoc.org. A dditional details are provided in the A MS Copyright } \\
\text { Policy statement, available on the AMS website (http:/Www.ametsoc.org/Copyrightl nformation). }\end{array}$ \\
\hline Tyре & article \\
\hline File Information & jhm-d-18-0095.1.pdf \\
\hline
\end{tabular}

Instructions for use 


\title{
Future Changes in Monthly Extreme Precipitation in Japan Using Large-Ensemble Regional Climate Simulations
}

\author{
DAISUKE HATSUZUKA AND TOMONORI SATO \\ Faculty of Environmental Earth Science, Hokkaido University, Sapporo, Japan
}

(Manuscript received 7 May 2018, in final form 17 January 2019)

\begin{abstract}
This study investigated future changes in monthly extreme precipitation in Japan during summer (JuneAugust). The uncertainties in estimating extreme monthly precipitation were analyzed using large-ensemble regional climate simulations for both present and $4-\mathrm{K}$ warmer climates. The main diagnostics were based on the 100-yr return values of monthly total precipitation $P_{\mathrm{T} 100}$ estimated from a best-fit probability distribution. Under the warmer climate, $P_{\mathrm{T} 100}$ was projected to increase in approximately $87 \%, 88 \%$, and $78 \%$ of the total number of stations for June, July, and August, respectively, suggesting that once-per-century monthly precipitation will increase as temperature increases over a wide area of Japan, although large regional variations will exist. The western part of Kyushu and the Hokkaido region showed significant and moderately robust increases in $P_{\mathrm{T} 100}$ throughout the summer months. In contrast, a considerable and robust increase was projected only in June in the Nansei Islands. The percentage change in $P_{\mathrm{T} 100}$ was small in western and eastern Japan, and thus the sign of the change was uncertain. Further analysis indicated that uncertainty in internal variability is more important than uncertainty in the SST scenario for future projections of monthly precipitation extremes.
\end{abstract}

\section{Introduction}

Changes in the intensity and frequency of extreme precipitation events under global warming have attracted considerable attention because of their potentially wide-ranging impacts in the fields of natural disasters, agriculture, and water resources. The intensity of extreme precipitation is projected to increase under a warmer climate in many regions of the world, even in regions where the mean precipitation might decrease (e.g., Kharin and Zwiers 2000; Wehner 2004; Emori and Brown 2005; Kharin et al. 2007; Pall et al. 2007; Russo and Sterl 2012). Climate-related projections of extreme precipitation have been concerned mostly with shortduration events (e.g., daily precipitation accumulation), as seen in the abovementioned works, which can be useful for impact assessments of natural disasters related to torrential downpours, for example, flash floods and landslides. However, Fischer and Knutti (2016) highlighted that "it is still poorly understood at what rate biweekly to monthly rainfall maxima increase." Such longer-duration extreme events are

Corresponding author: Daisuke Hatsuzuka, hatsuzuka@ees. hokudai.ac.jp often associated with sediment-related disasters and widespread flooding that can have devastating impacts on human life and agricultural yields. Therefore, regional climate projections of extreme precipitation are necessary at multiple time scales to support discussion of adaptation strategies intended to mitigate the risk of disasters related to heavy precipitation.

Extreme weather events are generally assessed using two types of approaches (Klein Tank et al. 2009). One is based on various extreme indices, such as annual maximum indices (e.g., Alexander et al. 2006; Tebaldi et al. 2006), which represent moderate extreme events because they typically occur once a year. Such indices allow monitoring of long-term trends and robust assessments of future changes in extreme events from reasonably small-sized ensemble simulations. The second common approach evaluates rare extreme events with return periods of more than several decades that correspond to the tail of a probability distribution. In particular, hydrological infrastructure such as dams and banks are designed with consideration of a certain return level, for which the period (typically 30-200 years) is determined depending on the purpose. The evaluation of such rare extreme events often depends on estimations based on the fitting of probability distribution functions. Previous 
studies have applied a generalized extreme value distribution to estimate the extreme values of annual or seasonal maxima (e.g., Russo and Sterl 2012; Kharin et al. 2013). In such analyses, long-term data under stationary climatic conditions (i.e., large-sized ensemble simulation data) are necessary to obtain reliable probability estimates for the rare extreme events.

Recently, a large-ensemble dataset has become available on the Database for Policy Decision Making for Future Climate Change (d4PDF), which comprises 5000-yr-scale ensemble simulations from a high-resolution AGCM with six different SST patterns for the future climate (Mizuta et al. 2017). Downscaled products produced by an RCM are also available in this dataset. The use of large-ensemble simulations enables estimation of extreme values with return periods of more than 100 years without the requirement of fitting to any probability distribution function (e.g., Kawase et al. 2016; Mizuta et al. 2017). Another advantage of the large ensemble is that the magnitudes of the uncertainties caused by internal variability can be evaluated in relation to future climate projections. Here, internal variability means the natural variability of the climate system that occurs in the absence of external forcing change, which introduces large uncertainties into projections of regional climate and climate extremes (Xie et al. 2015). Using global climate simulations of the d4PDF, Endo et al. (2017) investigated future changes in annual maximum daily precipitation over East Asia and their uncertainties arising from internal variability and external forcing (difference in future SST patterns). They revealed that the uncertainty is derived mainly from internal variability over land regions, whereas external forcing largely contributes to the uncertainty over oceanic regions.

Many earlier studies have focused on future changes in precipitation extremes on hourly or daily time scales around Japan (e.g., Kimoto et al. 2005; Iizumi et al. 2012; Yamada et al. 2014; Kawase et al. 2016), whereas the monthly time scale has been considered rarely for future projections. Japan is highly prone to shallow landslides because of its high-relief topography and complex geological conditions. Since the landslides often occur from both short (subdaily time scale) and long (submonthly time scale) rainfall events in Japan (e.g., Saito et al. 2010), it is expected that longer-duration precipitation extremes also play a role for the risk assessment of landslide disaster under a warmer climate. In the present study, we investigated the future changes in 100-yr return values of monthly precipitation in Japan and their uncertainties using regional climate simulations of the d4PDF. The target season is summer (June-August), which is when heavy precipitation events occur frequently in association

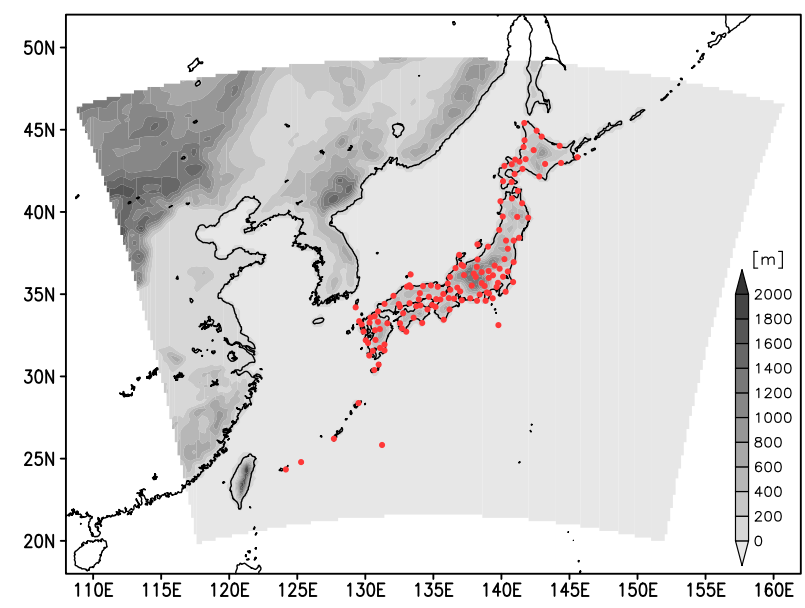

FIG. 1. Map of the domain for the d4PDF regional climate simulations. Grayscale shading shows topography. Red circles indicate locations of JMA observation stations used for analysis.

with the intrusion of warm humid air from the south. This study also focuses on the uncertainties introduced by internal variability and the differences in future SST patterns. The following section describes the datasets and the analysis methods used in this study. The results are outlined in section 3. Finally, a discussion and our conclusions are presented in sections 4 and 5, respectively.

\section{Data and methods}

\section{a. Model and experimental design}

To produce finescale climate projections over Japan, we used the regional data from $\mathrm{d} 4 \mathrm{PDF}$ for present and future climates, which was obtained using the nonhydrostatic RCM (NHRCM) developed by the Meteorological Research Institute of the JMA. The domain covered Japan, the Korean Peninsula, and the eastern part of the Asian continent with 20-km horizontal resolution (Fig. 1). Detailed specifications of the model are described in both Sasaki et al. (2008) and Murata et al. (2013).

Lateral boundary conditions for the $20-\mathrm{km}$-mesh NHRCM were provided by the approximately $60-\mathrm{km}$-mesh MRI-AGCM3.2H (Mizuta et al. 2012), the settings of which were described in Mizuta et al. (2017) and are summarized below. The present climate experiments were performed for 60 years (1951-2010) using observed SSTs and sea ice concentrations from COBE-SST2 (Hirahara et al. 2014), together with observed greenhouse gas concentrations. For the present climate, 100 ensemble members were generated from experiments with different initial atmospheric conditions and small perturbations in observed SST. The future climate 
experiments were performed for 60 years with a climate $4-\mathrm{K}$ warmer than preindustrial levels in terms of global mean surface air temperature, corresponding to conditions at around the end of the twenty-first century under the RCP8.5 scenario. Six different spatial patterns of $\Delta$ SST were applied to the future climate, which were projected using six coupled models that participated in CMIP5. By applying a scaling factor to each $\Delta$ SST pattern, the future simulations in the AGCM reproduced the climate $4 \mathrm{~K}$ warmer than preindustrial levels. Such ensemble AGCM experiments using the different SST pattern enable us to discuss on what part of the uncertainty in the projected climate change could be attributed to the uncertainty of the SST change (Mizuta et al. 2014). For each of the six $\Delta$ SST patterns, 15 -member ensemble experiments ( 90 members in total) were conducted using different initial conditions and small perturbations of SST, as with the present climate experiments. The small SST perturbations are the same as those used for the present simulation. Further details of the experimental designs of the d4PDF are described in Mizuta et al. (2017).

Limited computational resources meant that the regional climate simulations were conducted for only 50 members for the present climate. Hence, we analyzed 50 and 90 ensemble members for the present and future experiments, respectively. In this study, monthly total precipitation was computed from hourly outputs of the d4PDF regional data.

\section{b. Observational data}

The reproducibility of the d4PDF regional data was evaluated using JMA surface observational data available for the same period used for the present climate experiments of the d4PDF. As these data included some missing values, we selected 134 observation stations for monthly precipitation after performing a quality check (Fig. 1). For validation based on the observational locations, the model grids within $20 \mathrm{~km}$ of the observational station were averaged using the inverse distance weighting method, which is expressed as follows:

$$
\begin{gathered}
z=\sum_{i=1}^{n} w_{i} z_{i}, \\
w_{i}=\frac{d_{i}^{-p}}{\sum_{j=1}^{n} d_{j}^{-p}},
\end{gathered}
$$

where $z$ is the interpolated value at the observational station, $z_{i}$ is the simulated value and $w_{i}$ is the weight at the model grid $i$, and $n$ represents the number of grids within $20 \mathrm{~km}$ from the observational station. In the calculation of the weight, $p$ is a weighting power, which is given as a positive real number, and $d_{i}$ is the distance between the observational station and the model grid $i$. This indicates that the weight decreases as the distance increases. The weighting power also controls the degree of the weight at each grid; a larger power results in a heavier weight at nearby grids. This parameter is typically set to 2 (e.g., Oku and Nakakita 2013). Thus, $p=2$ has been used in this study.

\section{c. Extreme monthly precipitation}

As mentioned in the previous section, the largeensemble dataset enables estimation of extreme values by means of order statistics that do not require the fitting of probability distribution functions (Mizuta et al. 2017). However, we attempted to estimate extreme values for individual ensemble members because one of the important objectives of this study was to quantify the uncertainties in future climate projections, which are often evaluated by the ensemble spread (e.g., Endo et al. 2017). As an index of extreme monthly precipitation, 100 -yr return values of monthly precipitation $P_{\mathrm{T} 100}$ are used in this study. The 100 -yr return values were estimated based on the best-fit probability distribution for monthly precipitation for 60 years. The details of the method for the estimation of the extremes are described in the appendix. In the following section, we evaluate the reproducibility of $P_{\mathrm{T} 100}$ in the present climate, followed by an evaluation of the future changes in $P_{\mathrm{T} 100}$ and their uncertainties.

\section{Results}

\section{a. Present climate simulation}

Figure 2 shows the geographical distributions of $P_{\mathrm{T} 100}$ from June to August for the observations and the simulations. The observations indicate that $P_{\mathrm{T} 100}$ in June is $>800 \mathrm{~mm}$ in the Kyushu region, while it is $<400 \mathrm{~mm}$ in the northern part of Japan (Fig. 2a). The geographical distribution in July is similar to June but with a relatively large increase in the Hokkaido region (Fig. 2b). In August, the north-south difference in $P_{\mathrm{T} 100}$ is weakened significantly because of the decreased (increased) $P_{\mathrm{T} 100}$ in western Japan (northern Japan) (Fig. 2c). The observed geographical patterns in $P_{\mathrm{T} 100}$ were almost reproduced by the simulations in all summer months (Figs. 2d-f). However, it should be noted that the $P_{\mathrm{T} 100}$ has some biases as compared with observations (Figs. $2 \mathrm{~g}-\mathrm{i}$ ). In particular, a remarkable overestimation is observed at some stations in July and August.

To compare the magnitudes of the uncertainty between different stations, Fig. 3 shows the coefficients of 


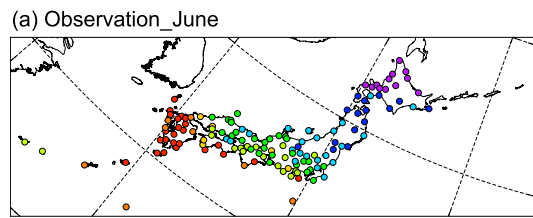

(b) Observation_July

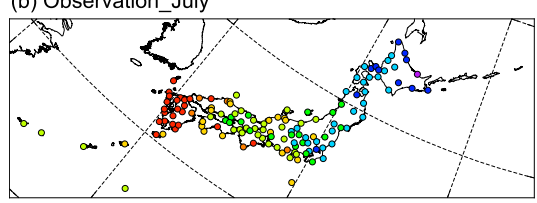

(c) Observation_August

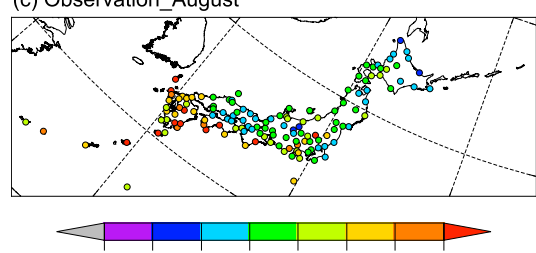

$100 \quad 200 \quad 300 \quad 400 \quad 500 \quad 600 \quad 700 \quad 800[\mathrm{~mm}]$

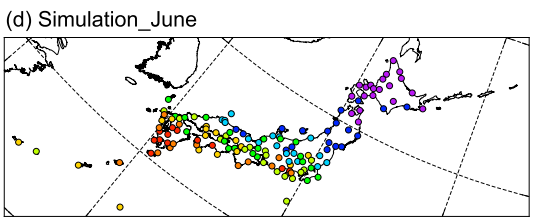

(e) Simulation_July
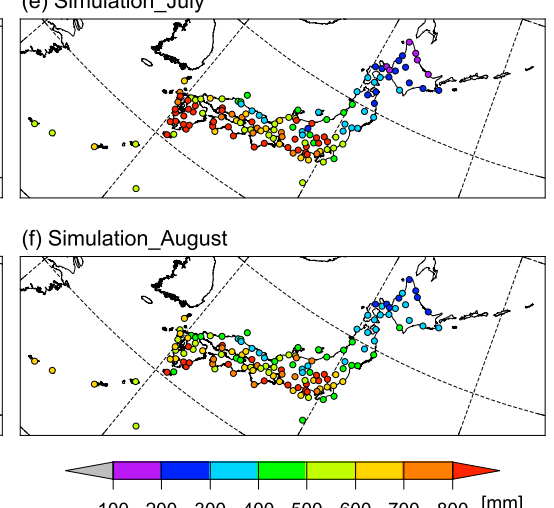

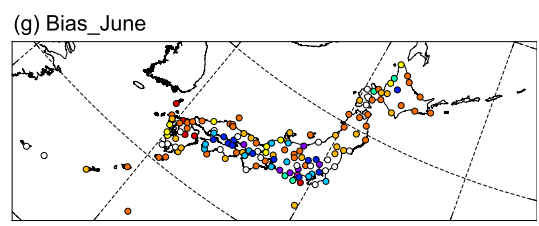

(h) Bias July

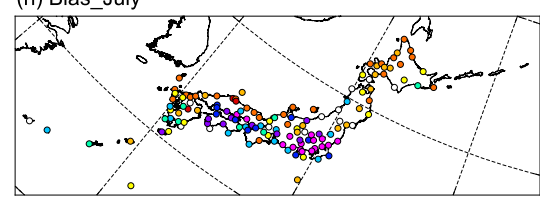

(i) Bias August

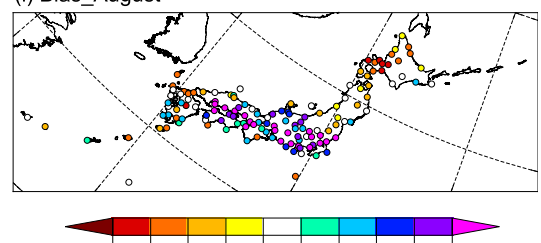

$40 \quad 6080 \quad 9095105110120140160[\%]$

FIG. 2. The 100-yr return values of monthly precipitation $P_{\text {T100 }}$ during June-August for (a)-(c) observations and (d)-(f) the present climate simulation. The present climate simulation is shown by ensemble averages of estimated return values. (g) $-(\mathrm{h})$ Ratio of $P_{\mathrm{T} 100}$ for the simulation relative to the observation expressed as a percentage.

variability (CVs) measured by the ensemble spread at each station. Because each ensemble member underwent the same external forcing (e.g., SST and greenhouse gases), the ensemble spread represents the uncertainty range arising mainly from internal climate variability. The CVs show values of $0.1-0.2$ at most stations throughout the summer months, except in the Nansei Islands in August, where the CVs are $>0.2$ at all stations (Fig. 3c). As tropical cyclones (TCs) are a major source of heavy precipitation in this region during August, the large CVs suggest that TC-associated extreme precipitation on the monthly time scale might include large uncertainties. This result highlights the benefit of using large-sized ensemble simulations to obtain robust future climate projections, especially in extreme events, because of the large uncertainty attributable to internal variability.

\section{b. Future change}

In this subsection, we estimate the future changes in climatological-mean and extreme monthly precipitation during summer. Here, the future changes are shown as percentage changes relative to the present climate based on their ensemble average. To evaluate the statistical significance in the future change, we also employed the Student's $t$ test (e.g., von Storch and Zwiers 1999).

Figures $4 \mathrm{a}-\mathrm{c}$ show the future changes in climatologicalmean monthly precipitation. In June, the amount of monthly precipitation decreases significantly in western and eastern Japan, whereas remarkable increases are found in both the Nansei Islands and the western part of Kyushu (Fig. 4a). In July, the geographical distribution of future change is similar to June but with significant increases in the Hokkaido region and along the Sea of Japan coast in both eastern and northern Japan (Fig. 4b). In August, the mean precipitation decreases significantly from western to eastern Japan, whereas it increases significantly both in the western part of Kyushu and in the Hokkaido region (Fig. 4c). Thus, summer precipitation is projected to decrease across a broad area of Japan in the future. This result differs from that seen in previous studies (e.g., Kusunoki et al. 2011; Endo et al. 2012), which showed the tendency of precipitation increase over Japan during summer. This difference may be caused by the differences in factors such as emission scenario, target period, and the distribution of SST.

Figures $4 \mathrm{~d}-\mathrm{f}$ shows the future changes in extreme monthly precipitation $P_{\mathrm{T} 100}$. In contrast to the mean precipitation, the $P_{\mathrm{T} 100}$ is projected to increase at 116 , 118 , and 104 stations (approximately $87 \%, 88 \%$, and $78 \%$ of the total number of stations) in June, July, and August, respectively. In June, the magnitude of the change is small in most areas of western and eastern Japan with low statistical significance (Fig. 4d), where the mean precipitation decreases significantly (Fig. 4a). In contrast, $P_{\mathrm{T} 100}$ shows significant increases in the Nansei Islands, western parts of Kyushu, and northern Japan. The most remarkable increase can be found in the Nansei Islands, where $P_{\mathrm{T} 100}$ is projected to increase by $>40 \%$ in the future climate. In July and August, the 
(a) CV_June

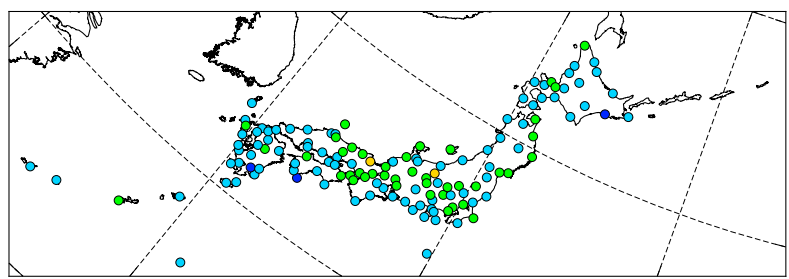

(b) CV_July

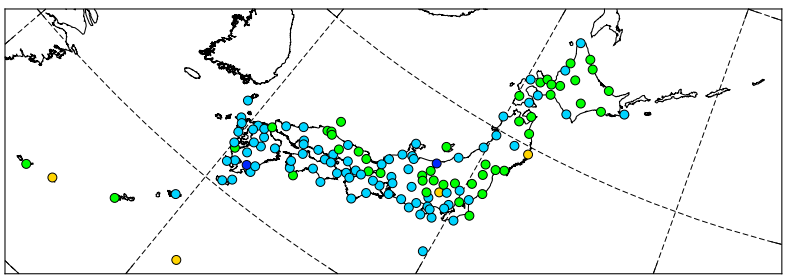

(c) CV_August

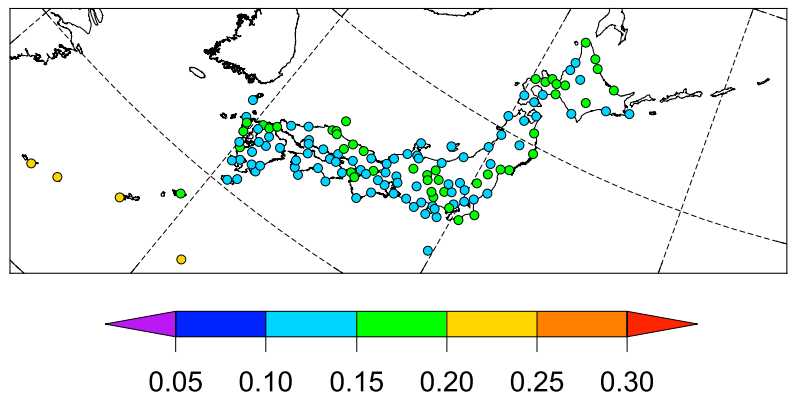

FIG. 3. CVs measured by the ensemble spread of $P_{\mathrm{T} 100}$ for the present climate simulation during June-August.

geographical distributions of the future changes are similar to June but with a larger number of stations with statistically significant increases (Figs. 4e,f). In these months, considerable increases $(>40 \%)$ are also projected in western parts of Kyushu and northern Japan, whereas a significant decrease is found only on the Sea of Japan side of western Japan during August. Consequently, significant increases in $P_{\mathrm{T} 100}$ are projected both in western parts of Kyushu and in the Hokkaido region throughout the summer months, suggesting an increased risk of floodrelated disasters under the future climate.

\section{c. Uncertainties}

This subsection investigates the uncertainties of future climate projections in $P_{\mathrm{T} 100}$ and their major sources. To investigate the sources of the uncertainty, we used the analysis of variance in a similar manner to Yip et al. (2011). Yip et al. (2011) included three components (i.e., scenario uncertainty, model uncertainty, and internal variability) to decompose the total uncertainty into its sources. In this study, the component of scenario uncertainty is not examined, as only the RCP 8.5 scenario is considered in the future simulations in the d4PDF. Here, we consider two sources of uncertainties: the difference in $\Delta$ SST patterns and internal variability. Based on Yip et al. (2011), an individual realization of the future changes $x$ for the $i$ th $\Delta$ SST pattern $(i=1,2, \ldots, 6)$ and the $j$ th member of the ensemble $(j=1,2, \ldots, 15)$ can be expressed as the sum of three components:

$$
x_{i j}=\mu+\delta_{i}+\varepsilon_{i j},
$$

where $\mu$ is the mean change of all simulations, $\delta_{i}$ is the deviation of $i$ th $\Delta$ SST pattern from $\mu$, and $\varepsilon_{i j}$ is the deviation of an individual ensemble from the ensemble mean of the corresponding $\Delta S S T$ pattern, representing the impact of internal variability.

The variances of $\varepsilon_{i j}$ and $\delta_{i}$ in Eq. (3) represent the uncertainties arising from internal variability $\hat{\sigma}_{\text {int }}^{2}$ and future SST changes $\hat{\sigma}_{\mathrm{EM}}^{2}$, respectively. However, the latter may include an influence of internal variability and thus overestimate the SST forcing uncertainty if not corrected. Hence, the corrected variance related to the difference in future SST patterns $\hat{\sigma}_{\Delta S S T}^{2}$ can be estimated as follows:

$$
\begin{aligned}
\hat{\sigma}_{\mathrm{int}}^{2} & =\frac{1}{N(n-1)} \sum_{i=1}^{N} \sum_{j=1}^{n}\left(x_{i j}-\bar{x}_{i}\right)^{2}, \\
\hat{\sigma}_{\mathrm{EM}}^{2} & =\frac{1}{N-1} \sum_{i=1}^{N}\left(\bar{x}_{i}-\overline{\bar{x}}\right)^{2}, \quad \text { and } \\
\hat{\sigma}_{\Delta \mathrm{SST}}^{2} & =\hat{\sigma}_{\mathrm{EM}}^{2}-\frac{1}{n} \hat{\sigma}_{\mathrm{int}}^{2},
\end{aligned}
$$

where $N$ is the number of different $\Delta$ SST patterns (i.e., $N=6$ ) and $n$ is the number of ensemble members (i.e., $n=15)$. Parameter $x_{i j}$ represents the future change rate (\%) for the $i$ th $\Delta$ SST pattern and the $j$ th member of the ensemble, $\bar{x}_{i}$ is the ensemble average of the $i$ th $\Delta$ SST pattern, and $\overline{\bar{x}}$ is the average of all data. Following previous studies (e.g., Rowell et al. 1995; Endo et al. 2017), the second term in Eq. (6) is added to extract the effect of internal variability. The derivation of this term is also described in the supporting information of Ruosteenoja et al. (2016). In Eqs. (4)-(6), the future change rates are given as percentage changes relative to the present climate ensemble average.

From Eqs. (4) and (6), the total uncertainty $\hat{\sigma}_{\text {tot }}^{2}$ is defined as the sum of two variance components:

$$
\hat{\sigma}_{\text {tot }}^{2}=\hat{\sigma}_{\Delta S S T}^{2}+\hat{\sigma}_{\text {int }}^{2} .
$$

Note that although we also presented a similar result of ensemble variability in Fig. 3, it denotes the variability of $P_{\mathrm{T} 100}$ in the present climate not for the future projections. 
(a) Mean_June

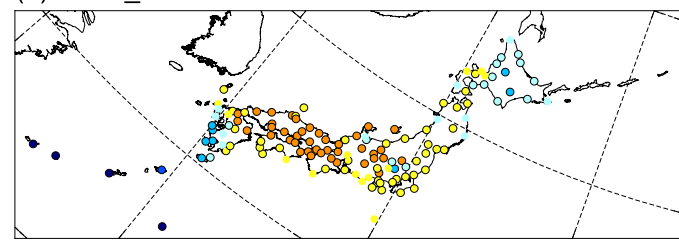

(b) Mean_July

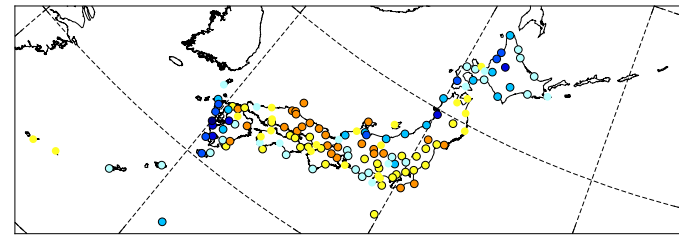

(c) Mean_August

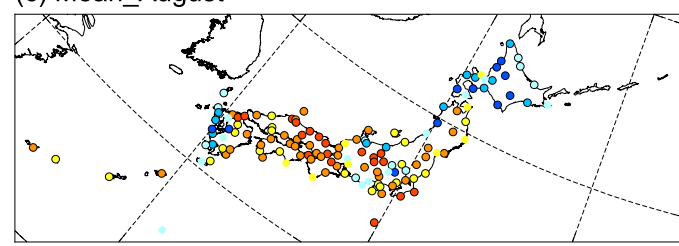

(d) Extreme June

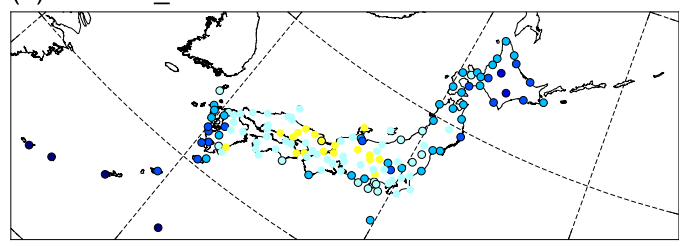

(e) Extreme_July

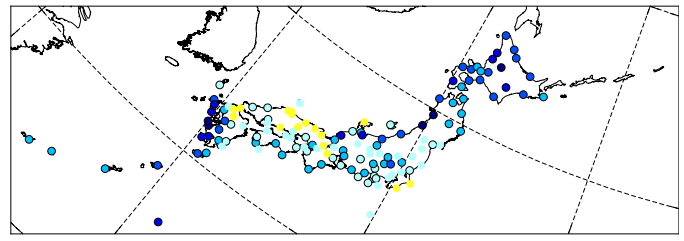

(f) Extreme_August

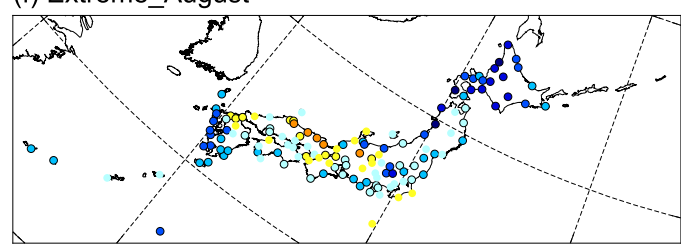

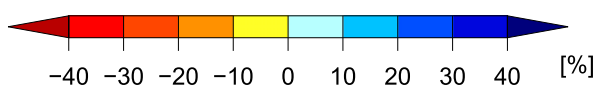

FIG. 4. Future changes in (a)-(c) climatological-mean monthly precipitation and (d)-(f) $P_{\mathrm{T} 100}$ during JuneAugust. Future changes were calculated from ensemble averages for present and future climate simulations, which are shown as percentage changes relative to the present climate. Circles with bold outlines denote changes statistically significant at the $1 \%$ level.

Figure 5 shows the all-station averages of the ensemble-mean future change $\Delta \hat{\mu}$ and each variance component $\left(\hat{\sigma}_{\text {tot }}, \hat{\sigma}_{\Delta \mathrm{SST}}\right.$, and $\left.\hat{\sigma}_{\text {int }}\right)$ for mean and extreme monthly precipitation. Note that the term $\hat{\sigma}_{\text {int }}$ for the mean precipitation is derived mainly from the different initial atmospheric conditions used for ensemble experiments (Endo et al. 2017), while for the extreme monthly precipitation the $\hat{\sigma}_{\text {int }}$ may include the effect of small perturbations in SST as well as the different initial conditions. For changes in the ensemble average $\Delta \hat{\mu}$, mean precipitation tends to decrease or remains nearly unchanged in the future, whereas $P_{\mathrm{T} 100}$ shows significant increases through the summer months. However, the projected changes also have large uncertainties in both mean and extreme precipitation because $\hat{\sigma}_{\text {tot }}$ is much larger than the magnitude of $\Delta \hat{\mu}$. The main sources contributing to the uncertainties $\hat{\sigma}_{\text {tot }}$ are different between mean and extreme monthly precipitation. For $P_{\mathrm{T} 100}$, internal variability $\hat{\sigma}_{\text {int }}$ makes a significant contribution to $\hat{\sigma}_{\text {tot }}$, whereas for mean precipitation the contribution from the $\Delta$ SST pattern $\hat{\sigma}_{\Delta S S T}$ is comparable with that of $\hat{\sigma}_{\text {int }}$. Endo et al. (2017) also showed that the contribution of $\hat{\sigma}_{\text {int }}$ to $\hat{\sigma}_{\text {tot }}$ is larger in precipitation extremes compared with the total precipitation. Thus, these results indicate the importance of uncertainties of climate projections arising from internal variability, especially in extreme events. On the other hand, they demonstrated a robust increase (i.e., much larger $\Delta \hat{\mu}$ than $\hat{\sigma}_{\text {tot }}$ ) in precipitation extremes around Japan using indices of different time scales (i.e., 1-, 3-, and 10-day precipitation totals), which is different from our result that the projected change in extreme monthly precipitation has large uncertainties. In Fig. 5b, we found that the large uncertainty in $P_{\mathrm{T} 100}$ change is attributed to the uncertainty arising from internal variability $\hat{\sigma}_{\text {int }}$. One possible reason for the large $\hat{\sigma}_{\text {int }}$ in $P_{\mathrm{T} 100}$ is that the approach for extreme value analysis is different in the two studies as introduced in section 1; the indices used in Endo et al. (2017) are based on annual statistics, whereas our study targeted rare extreme events with 100 -yr return periods.

To understand the regional characteristics of uncertainty in the future projections, Figs. 6a-f show the geographical distributions of $\Delta \hat{\mu}$ and $\hat{\sigma}_{\text {tot }}$ for $P_{\text {T100. The }}$ total uncertainties $\hat{\sigma}_{\text {tot }}$ typically have a range of $10 \%-30 \%$ with unclear regional variations (Figs. 6d-f). This means there are large uncertainties in the sign of $\Delta \hat{\mu}$ from western to eastern Japan, that is, $P_{\mathrm{T} 100}$ is potentially increased 

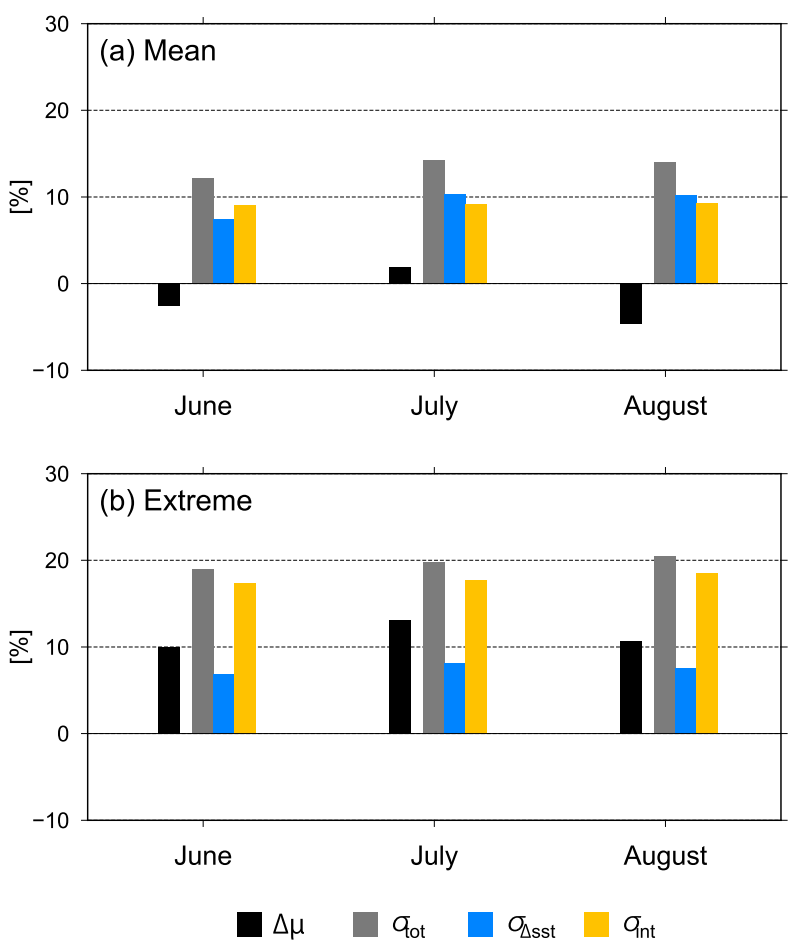

FIG. 5. Future percentage changes and their uncertainties for (a) climatological-mean monthly precipitation and (b) $P_{\mathrm{T} 100}$, averaged over all stations. Each bar represents the following: $\Delta \hat{\mu}$ (black) is ensemble-mean future change, $\hat{\sigma}_{\text {tot }}$ (gray) is ensemble spread among all members, $\hat{\sigma}_{\Delta S S T}$ (blue) is ensemble spread arising from the difference in future SST patterns, and $\hat{\sigma}_{\text {int }}$ (yellow) is ensemble spread arising from internal variability.

by the rate of $10 \%-30 \%$, even in regions where the magnitude of $\Delta \hat{\mu}$ is very small. In contrast, there is a high possibility of an increase in $P_{\mathrm{T} 100}$ in regions with large $\Delta \hat{\mu}$ (e.g., the western part of Kyushu and the Hokkaido region), because $\Delta \hat{\mu}$ is larger than or comparable with $\hat{\sigma}_{\text {tot }}$ in such areas. More specifically, robust increases in $P_{\mathrm{T} 100}$ are projected in the Nansei Islands in June, the western part of Kyushu in July, and the Hokkaido region in August.

Figures $6 \mathrm{~g}-\mathrm{i}$ show the geographical distributions of the ratio of $\hat{\sigma}_{\Delta \mathrm{SST}}$ to $\hat{\sigma}_{\text {int }}$ for $P_{\mathrm{T} 100}$, representing the relative importance of the difference in the $\Delta$ SST pattern and internal variability to the total uncertainties in the future projections. Although the contributions from internal variability are larger than from the future SST pattern in the entire region, the relative importance of these two sources varies according to region. In the Hokkaido region, $\hat{\sigma}_{\Delta S S T}$ is much smaller than $\hat{\sigma}_{\text {int }}$, indicating internal atmospheric variability is the major source of the uncertainty in $P_{\mathrm{T} 100}$ change. On the other hand, we find a relatively large contribution from the future SST pattern to the total uncertainty in western Japan through the summer months, with the exception of the Nansei
Islands, where the future SST pattern contributes largely to the uncertainty only in June. This suggests that reliable projection of SST pattern in the future climate leads to a reduction of the uncertainty in $P_{\mathrm{T} 100}$ change in these regions. The difference in the SST pattern affects the largescale circulation change through a variation in sea level pressure. Thus, it is also suggested that the higher contribution of $\hat{\sigma}_{\Delta S S T}$ in the lower latitudes will be attributed to the change in moisture flux and its convergence associated with the northwestern Pacific subtropical high. We will further discuss the geographical difference in these uncertainty sources in the next section.

\section{Discussion}

In the previous section, we examined the large contribution of internal variability to the uncertainties in future projections of $P_{\mathrm{T} 100}$ across Japan. In particular, the Hokkaido region, where $P_{\mathrm{T} 100}$ is projected to increase significantly, is associated with internal variability. To identify a key process that might affect extreme monthly precipitation in this region, we examined largescale atmospheric circulation fields using the d4PDF data derived from 60-km-mesh MRI-AGCM simulations. Here, we consider the year when the maximum monthly precipitation occurred in each ensemble member for each month (i.e., 60-yr maximum monthly precipitation) as extreme events. The total number of events used for the composite analysis is 1000 (50 ensembles $\times 20$ stations) in the present climate simulation and 1800 ( 90 ensembles $\times$ 20 stations) in the future climate simulation. Figure 7 shows composites of $850-\mathrm{hPa}$ geopotential height, vertically integrated moisture flux, and $500-\mathrm{hPa}$ geopotential height anomalies based on the maximum monthly precipitation events in the Hokkaido region in August. In the present climate simulation, a southerly moisture flux anomaly is dominant over this region, accompanied by an anticyclonic circulation anomaly to the east of Japan and a cyclonic circulation anomaly to the south of western Japan in the low-level troposphere (Fig. 7a). In the midtroposphere, a wave train structure is evident along the subtropical jet stream (Fig. 7b). This result closely resembles the overall pattern of anomalies in August 2016, when unprecedented monthly precipitation occurred in Hokkaido (see Fig. 1 of Takemura et al. 2017). Takemura et al. (2017) also reported that anomalous TC activity, modulated by blocking high pressure to the east of Japan, induced the extreme precipitation event in August 2016. It is well known that such atmospheric blocking events are often associated with extreme temperature and precipitation anomalies over the surrounding area (e.g., Matsueda 2011; Lau and Kim 2012). For the future climate simulation, a similar barotropic synoptic 


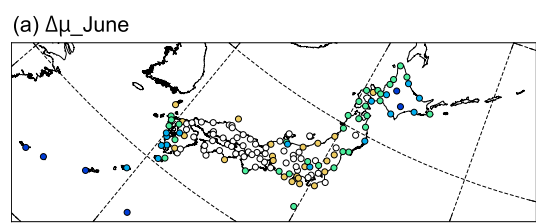

(b) $\Delta \mu \_J u l y$
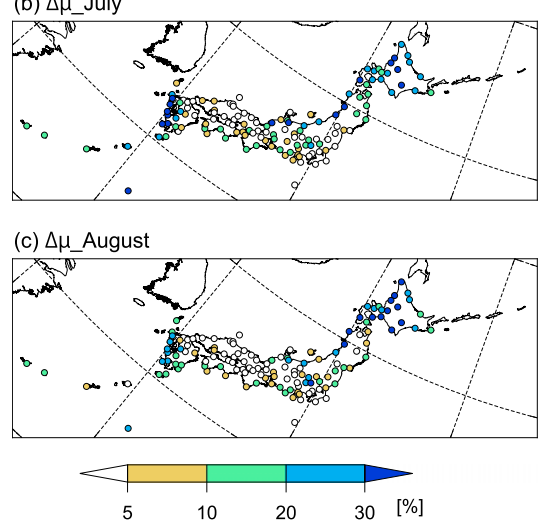

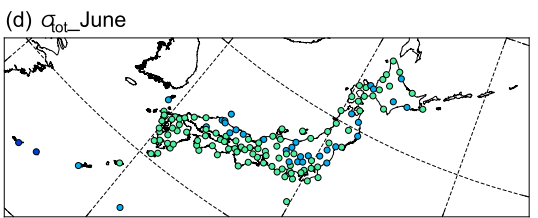

(e) Got_July
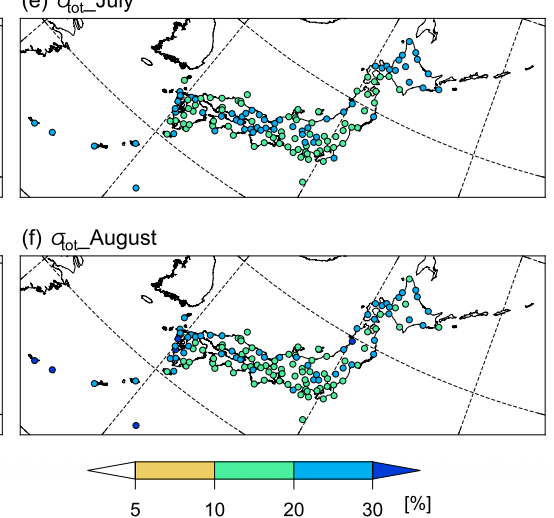

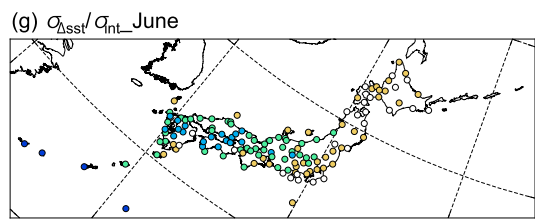

(h) $\sigma_{\Delta s s t} / \sigma_{\text {nt_-July }}$
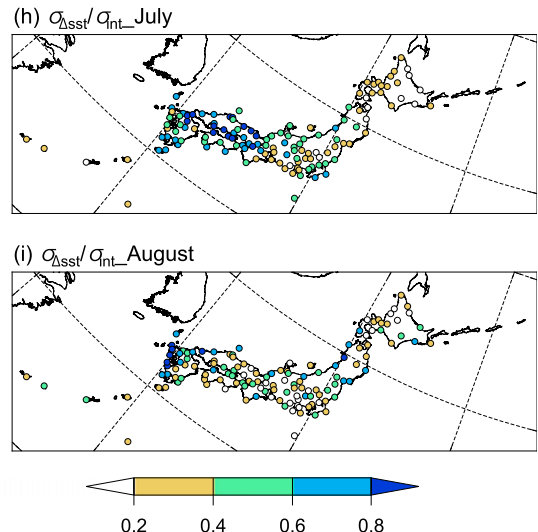

FIG. 6. Geographical distributions of (a)-(c) $\Delta \hat{\mu}$, (d)-(f) $\hat{\sigma}_{\text {tot }}$, and (g)-(i) ratio of $\hat{\sigma}_{\Delta \mathrm{SST}}$ to $\hat{\sigma}_{\text {int }}$ during June-August for $P_{\text {T100. Note that }}$ (a)-(c) are as in Figs. $4 d-f$, but the color bar is different.

pattern was found in association extreme monthly precipitation events in the Hokkaido region (Figs. 7c,d), suggesting that future extreme events are maintained by internal atmospheric processes similar to the present climate. In addition, although further analysis will be necessary to identify the cause of internally induced uncertainty, this result suggests that the activity of blocking highs (such as the location, duration, and amplitude of the anomaly) might introduce the large uncertainty associated with the internal variability in the Hokkaido region.

Some regions showed reasonably high contributions from the difference in future SST patterns to the total uncertainties, for example, the Nansei Islands in June and western Japan during July-August. Recently, Okada et al. (2017) revealed that the differences in future SST patterns in July and August have significant impact on the termination timing of the baiu season, whereas the mean circulation changes in June are similar across all SST patterns. Figure 8 also shows future changes in climatological-mean moisture flux during June-August for three representatives out of six SST patterns according to Mizuta et al. (2014), which support the results of Okada et al. (2017). For example, the CCSM4 SST-forced simulations show enhancement of the southwesterly moisture inflow over western and eastern Japan in July and August (Figs. 8b,c), whereas no robust anomalies were found in the ensemble members using MIROC5 (Figs. 8e,f) and MRICGCM3 (Figs. 8h,i) SST patterns. These results suggest that changes in large-scale atmospheric circulations forced by SST anomalies introduce the uncertainty in future projections of $P_{\mathrm{T} 100}$ in these regions, with its high contribution rates in western Japan. In contrast, in June, the changes in atmospheric circulation are similar among the three SST patterns (Figs. 8a,d,g). This suggests that the future SST pattern might contribute to the uncertainties in extreme precipitation on the monthly time scale in the Nansei Islands through modulation of TC activity, because changes in TC activity (e.g., genesis frequency and intensity) also depend largely on the SST warming pattern (e.g., Mei and Xie 2016; Yoshida et al. 2017). The future change in baiu termination can be explained by the large-scale circulation response to future change in tropical SST patterns such as an El Niño-like or non-El Niño-like pattern (Okada et al. 2017), whereas local SST may also have an important role in the TC-related precipitation through local TC development (Mei and Xie 2016). Although we did not examine the relative importance of tropical and local SST in the extreme monthly precipitation, it is expected that reliable projection of the SST pattern in the future climate would lead to a reduction of the uncertainty in these regions.

Although we have demonstrated the future change in extreme monthly precipitation and its uncertainty in Japan, there are limitations resulting from the use of the monthly dataset. For example, we have not considered how monthly time scale extremes relate to higherfrequency extremes such as daily precipitation extremes. If we can find the regional differences between monthly precipitation extremes driven by a few intense daily precipitation events and that driven by persistent small amount of daily precipitation, it would be useful to better 
(a) $850 \mathrm{hPa} Z$ \& WVFlux anomaly Present

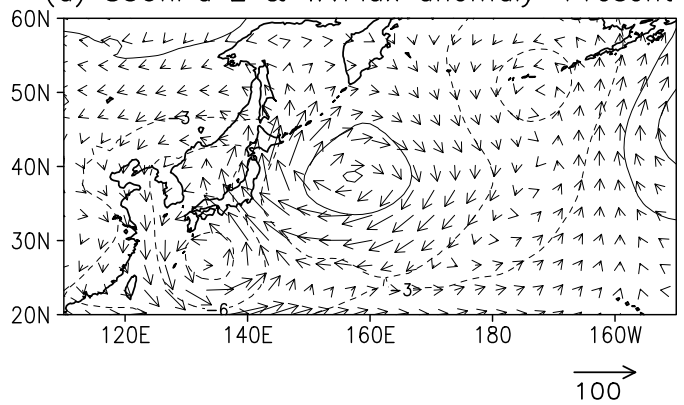

(c) $850 \mathrm{hPa} Z$ \& WVFlux anomaly Future

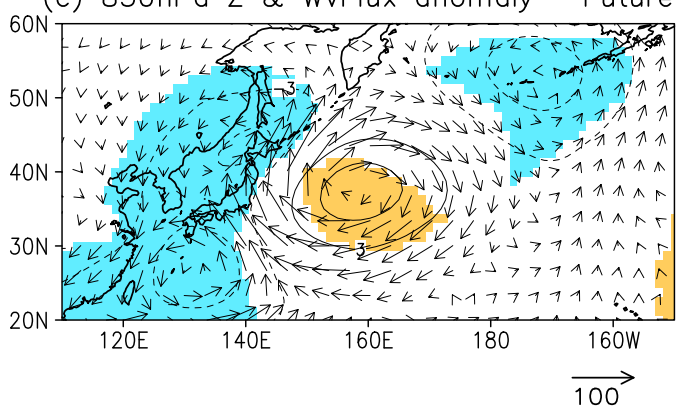

(b) $500 \mathrm{hPa} \mathrm{Z}$ anomaly

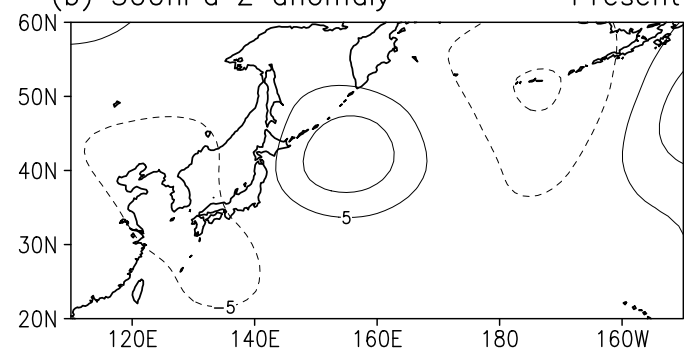

FIG. 7. Composite anomalies of (a) 850-hPa geopotential height and vertically integrated moisture flux vectors $\left(\mathrm{kg} \mathrm{m}^{-1} \mathrm{~s}^{-1}\right.$ ) and (b) 500-hPa geopotential height in the maximum monthly precipitation events in the Hokkaido region in August for the present climate. (c),(d) As in (a) and (b), respectively, but for the future climate. Anomalies in the present and future climates were defined as the departure from climatological mean fields for each climate. Orange (blue) shading denotes grids that have a positive (negative) anomaly in all experiments for ensemble averages in each SST pattern. The contour interval for $850-(500) \mathrm{hPa}$ geopotential height is 3 (5) $\mathrm{m}$. Zero contours are omitted.

understand the uncertainty associated with internal variability and future SST patterns. This topic should be investigated in a future work.

\section{Conclusions}

Future changes in monthly precipitation extremes in Japan under a 4-K warmer climate were investigated using large-ensemble regional climate simulations. The main diagnostics were based on the 100 -yr return values of monthly precipitation $P_{\mathrm{T} 100}$ estimated from a best-fit probability distribution. The ensemble-mean $P_{\mathrm{T} 100}$ was projected to increase in approximately $87 \%, 88 \%$, and $78 \%$ of the total number of stations for June, July, and August, respectively. In western and eastern Japan, the magnitude of the ensemble-mean changes in $P_{\mathrm{T} 100}$ was small through the summer months in comparison with the ensemble spread among all members, indicating that uncertainties remain regarding the sign of the change. Conversely, the future changes in $P_{\mathrm{T} 100}$ exhibited significant and moderately robust increases both in western Kyushu and in the Hokkaido region for all months. The Nansei Islands were an exception where a considerable and robust increase in $P_{\mathrm{T} 100}$ was projected only in June.
Some previous studies have projected a delay in the northward movement of the baiu front in the future climate, as well as increases in monthly precipitation to the south of Japan in June (e.g., Kanada et al. 2012; Okada et al. 2017), which could probably contribute to significant increases in $P_{\mathrm{T} 100}$ in the Nansei Islands. Further investigation based on ANOVA revealed that uncertainty in internal variability is more important than uncertainty in the SST scenario for future projections of $P_{\mathrm{T} 100}$ across Japan.

Our results regarding precipitation extremes on the monthly time scale differ from those on the daily time scale (e.g., Fig. 10 in Mizuta et al. 2017). For example, significant increases were projected for daily precipitation extremes over Japan, whereas the changes were not clearly identified for monthly precipitation extremes, especially from western to eastern Japan during summer. This difference is probably attributable to increased lengths of dry spells, together with the intensification of precipitation intensity, because warming leads to increases in the intensity and duration of drought through changes in the hydrological cycle, for example, the acceleration of land surface drying and longer recharge time for saturation (e.g., Giorgi et al. 2011; 

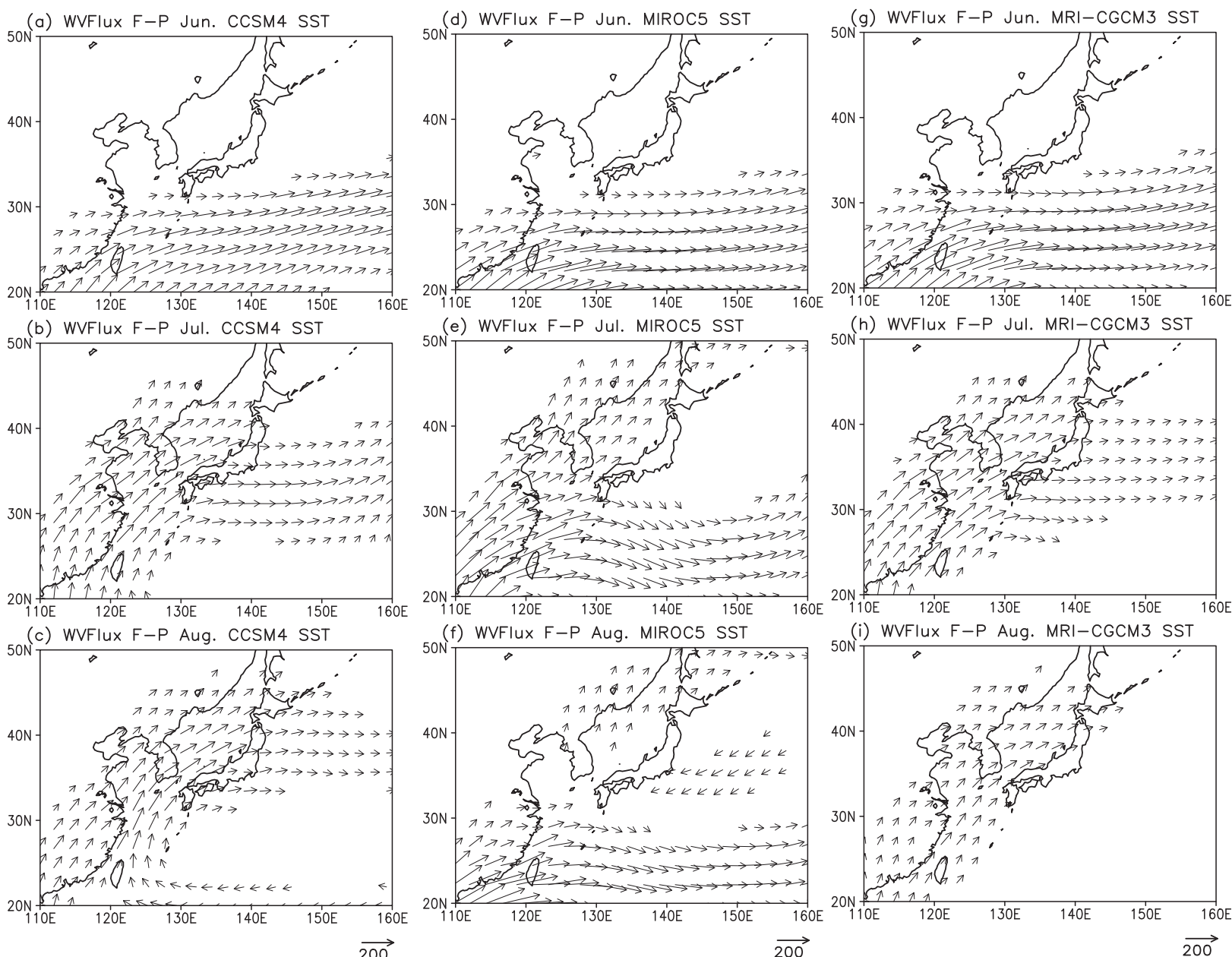

FIG. 8. Future changes of climatological-mean vertically integrated moisture flux during June-August for three different SST patterns. (a)-(c) CCSM4, (d)-(f) MIROC5, and (g)-(i) MRI-CGCM3. Only moisture flux vectors $>50 \mathrm{~kg} \mathrm{~m}^{-1} \mathrm{~s}^{-1}$ are plotted.

Trenberth 2011). This result highlights the importance of future projections for extremes on the scale of months as well as shorter periods. Further analysis is needed regarding the physical mechanisms related to the internal variability causing such extreme precipitation events, which would be expected to reduce the uncertainties in their future projections.

Acknowledgments. This research was supported by the Social Implementation Program on Climate Change Adaptation Technology (SI-CAT), Integrated Research Program for Advancing Climate Models (TOUGOU) of MEXT, JAPAN, and Grant-in-Aid for Young Scientists (A-15H05464) of the JSPS. This study utilized the Database for Policy Decision making for Future Climate Change (d4PDF) dataset, which is available from the DIAS website (http://www.editoria.u-tokyo.ac.jp/projects/ dias.old2/?locale $=$ en). The authors thank Dr. T. J. Yamada and reviewers for helpful comments and suggestions.

\section{APPENDIX}

\section{Estimation Method}

In this appendix, we explain the method we have used to estimate the $100-\mathrm{yr}$ return values of monthly precipitation. In this study, the $100-$ yr return values are estimated from the best-fit probability distribution for each ensemble member. Based on analysis of 10 probability distributions, Yue and Hashino (2007) reported that the lognormal and Pearson type 3 distributions provide good fits to monthly precipitation in Japan for all months. Sogawa and Suzuki (2008) tested three probability distributions and they found that the Pearson type 3 provided the best-fit distribution at most stations in Japan. Following Sogawa and Suzuki (2008), we also selected three candidate probability distributions: normal, lognormal, and Pearson type 3 . To determine the best-fit distribution among the three candidates, we conducted 
(a) Observation

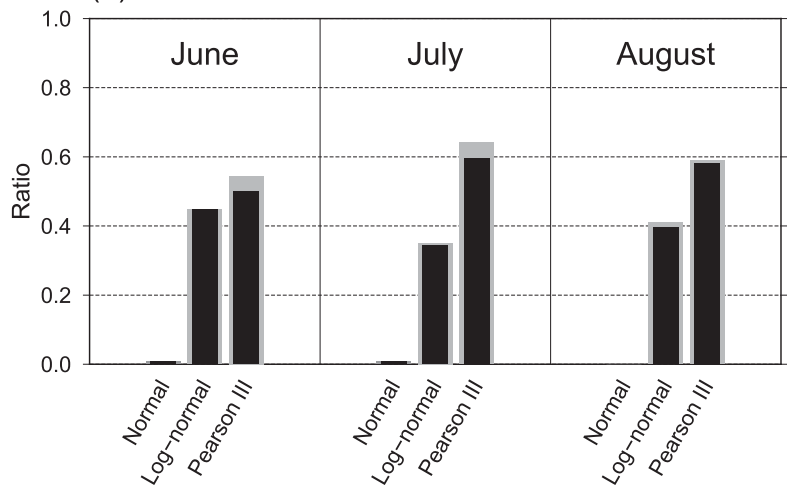

(b) Present climate simulation

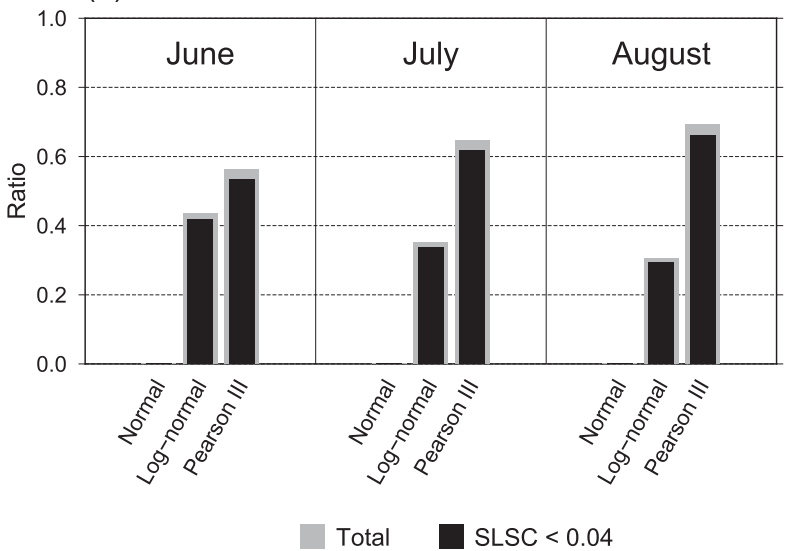

FIG. A1. Fractions of stations selected based on best-fit probability distribution types for each month and for (a) observations and (b) the present climate simulation. The ratio of 1.0 corresponds to the total number of stations $(N=134)$ for (a) and the total number of stations multiplied by the number of ensembles $(N=6700)$ for (b). Black bars represent the same but for a fitting satisfying SLSC $\leq 0.04$.

goodness-of-fit evaluations using the standard least squares criterion (SLSC; Takara and Takasao 1988), which is based on the difference between the exceedance probabilities obtained by plotting position formula and probability distribution estimation. In general, the fitted probability distributions can be considered adequate when the SLSC value is $<0.04$. Finally, the probability distribution with the smallest SLSC value was identified as the best-fit result. Figure A1 shows which distribution type was selected as the best-fit result for both the observation and the present climate simulation, depicted as the fraction of selected stations relative to the total number of station $(N=134)$. Note that the estimates of the extreme monthly precipitation made under the assumption of stationary conditions for the observation and the present climate simulation. The assessment for the observation (Fig. A1a) indicates the Pearson type 3 was selected at the largest number of stations for all months, whereas the normal distribution was selected at few stations, which is consistent with Sogawa and Suzuki (2008). The present climate simulation (Fig. A1b) shows almost the same ratios as the observations with a sufficient goodness of fit, indicating that the simulated monthly precipitation reproduced the observed features well. Future climate projections are assessed by the difference in 100 -yr return values between present and future climates estimated here.

\section{REFERENCES}

Alexander, L. V., and Coauthors, 2006: Global observed changes in daily climate extremes of temperature and precipitation. J. Geophys. Res., 111, D05109, https://doi.org/ 10.1029/2005JD006290.

Emori, S., and S. J. Brown, 2005: Dynamic and thermodynamic changes in mean and extreme precipitation under changed climate. Geophys. Res. Lett., 32, L17706, https://doi.org/ 10.1029/2005GL023272.

Endo, H., A. Kitoh, T. Ose, R. Mizuta, and S. Kusunoki, 2012: Future changes and uncertainties in Asian precipitation simulated by multiphysics and multi-sea surface temperature ensemble experiments with high-resolution Meteorological Research Institute atmospheric general circulation models (MRI-AGCMs). J. Geophys. Res., 117, D16118, https://doi.org/10.1029/2012JD017874.

,,-- R. Mizuta, and M. Ishii, 2017: Future changes in precipitation extremes in East Asia and their uncertainty based on large ensemble simulations with a high-resolution AGCM. SOLA, 13, 7-12, https://doi.org/10.2151/sola.2017-002.

Fischer, E. M., and R. Knutti, 2016: Observed heavy precipitation increase confirms theory and early models. Nat. Climate Change, 6, 986-991, https://doi.org/10.1038/nclimate3110.

Giorgi, F., E.-S. Im, E. Coppola, N. S. Diffenbaugh, X. J. Gao, L. Mariotti, and Y. Shi, 2011: Higher hydroclimatic intensity with global warming. J. Climate, 24, 5309-5324, https://doi.org/ 10.1175/2011JCLI3979.1.

Hirahara, S., M. Ishii, and Y. Fukuda, 2014: Centennial-scale sea surface temperature analysis and its uncertainty. J. Climate, 27, 57-75, https://doi.org/10.1175/JCLI-D-12-00837.1.

Iizumi, T., and Coauthors, 2012: Future change of daily precipitation indices in Japan: A stochastic weather generatorbased bootstrap approach to provide probabilistic climate information. J. Geophys. Res., 117, D11114, https://doi.org/ 10.1029/2011JD017197.

Kanada, S., M. Nakano, and T. Kato, 2012: Projections of future changes in precipitation and the vertical structure of the frontal zone during the Baiu season in the vicinity of Japan using a 5-km-mesh regional climate model. J. Meteor. Soc. Japan, 90A, 65-86, https://doi.org/10.2151/ jmsj.2012-A03.

Kawase, H., A. Murata, R. Mizuta, H. Sasaki, M. Nosaka, M. Ishii, and I. Takayabu, 2016: Enhancement of heavy daily snowfall in central Japan due to global warming as projected by large ensemble of regional climate simulations. Climatic Change, 139, 265-278, https://doi.org/10.1007/s10584-016-1781-3.

Kharin, V. V., and F. W. Zwiers, 2000: Changes in the extremes in an ensemble of transient climate simulations with a coupled atmosphere-ocean GCM. J. Climate, 13, 3760-3788, https:// doi.org/10.1175/1520-0442(2000)013<3760:CITEIA >2.0.CO;2. 
,,-- X. Zhang, and G. C. Hegerl, 2007: Changes in temperature and precipitation extremes in the IPCC ensemble of global coupled model simulations. J. Climate, 20, 1419-1444, https://doi.org/10.1175/JCLI4066.1.

,,--- , and M. Wehner, 2013: Changes in temperature and precipitation extremes in the CMIP5 ensemble. Climatic Change, 119, 345-357, https://doi.org/10.1007/s10584-013-0705-8.

Kimoto, M., N. Yasutomi, C. Yokoyama, and S. Emori, 2005: Projected changes in precipitation characteristics around Japan under the global warming. SOLA, 1, 85-88, https://doi.org/ 10.2151/sola.2005-023.

Klein Tank, A. M. G., F. W. Zwiers, and X. Zhang, 2009: Guidelines on analysis of extremes in a changing climate in support of informed decisions for adaptation. WCDMP-72, WMO/TD-1500, 56 pp., www.wmo.int/datastat/documents/ WCDMP_72_TD_1500_en_1_1.pdf.

Kusunoki, S., R. Mizuta, and M. Matsueda, 2011: Future changes in the East Asian rain band projected by global atmospheric models with $20-\mathrm{km}$ and $60-\mathrm{km}$ grid size. Climate Dyn., 37, 2481-2493, https://doi.org/10.1007/s00382-011-1000-x.

Lau, W. K. M., and K.-M. Kim, 2012: The 2010 Pakistan flood and Russian heat wave: Teleconnection of hydrometeorology extremes. J. Hydrometeor., 13, 392-403, https://doi.org/10.1175/ JHM-D-11-016.1.

Matsueda, M., 2011: Predictability of Euro-Russian blocking in summer of 2010. Geophys. Res. Lett., 38, L06801, https://doi.org/ 10.1029/2010GL046557.

Mei, W., and S.-P. Xie, 2016: Intensification of landfalling typhoons over the northwest Pacific since the late 1970s. Nat. Geosci., 9, 753-757, https://doi.org/10.1038/ngeo2792.

Mizuta, R., and Coauthors, 2012: Climate simulations using MRIAGCM3.2 with 20-km grid. J. Meteor. Soc. Japan, 90A, 233 258, https://doi.org/10.2151/jmsj.2012-A12.

— O. Orakawa, T. Ose, S. Kusunoki, H. Endo, and A. Kitoh, 2014: Classification of CMIP5 future change climate responses by the tropical sea surface temperature changes. SOLA, 10, 167-171, https://doi.org/10.2151/sola.2014-035.

— , and Coauthors, 2017: Over 5,000 years of ensemble future climate simulations by $60-\mathrm{km}$ global and $20-\mathrm{km}$ regional atmospheric models. Bull. Amer. Meteor. Soc., 98, 1383-1398, https://doi.org/10.1175/BAMS-D-16-0099.1.

Murata, A., H. Sasaki, M. Hanafusa, and K. Kurihara, 2013: Estimation of urban heat island intensity using biases in surface air temperature simulated by a nonhydrostatic regional climate model. Theor. Appl. Climatol., 112, 351-361, https://doi.org/ 10.1007/s00704-012-0739-2.

Okada, Y., T. Takemi, H. Ishikawa, S. Kusunoki, and R. Mizuta, 2017: Future changes in atmospheric conditions for the seasonal evolution of the Baiu as revealed from projected AGCM experiments. J. Meteor. Soc. Japan, 95, 239-260, https://doi.org/ 10.2151/jmsj.2017-013.

Oku, Y., and E. Nakakita, 2013: Future change of the potential landslide disasters as evaluated from precipitation data simulated by MRI-AGCM3.1. Hydrol. Processes, 27, 3332-3340, https://doi.org/10.1002/hyp.9833.

Pall, P., M. R. Allen, and D. A. Stone, 2007: Testing the ClausiusClapeyron constraint on changes in extreme precipitation under $\mathrm{CO}_{2}$ warming. Climate Dyn., 28, 351-363, https://doi.org/ 10.1007/s00382-006-0180-2.

Rowell, D. P., C. K. Folland, K. Maskell, and M. N. Ward, 1995: Variability of summer rainfall over tropical North Africa (1906-92): Observations and modelling. Quart. J. Roy. Meteor. Soc., 121, 669-704, https://doi.org/10.1002/qj.49712152311.
Ruosteenoja, K., J. Räisänen, A. Venäläinen, and M. Kämäräinen, 2016: Projections for the duration and degree days of the thermal growing season in Europe derived from CMIP5 model output. Int. J. Climatol., 36, 3039-3055, https://doi.org/10.1002/ joc. 4535 .

Russo, S., and A. Sterl, 2012: Global changes in seasonal means and extremes of precipitation from daily climate model data. J. Geophys. Res., 117, D01108, https://doi.org/10.1029/ 2011JD016260.

Saito, H., D. Nakayama, and H. Matsuyama, 2010: Relationship between the initiation of a shallow landslide and rainfall intensity-duration thresholds in Japan. Geomorphology, 118, 167-175, https://doi.org/10.1016/j.geomorph.2009.12.016.

Sasaki, H., K. Kurihara, I. Takayabu, and T. Uchiyama, 2008: Preliminary experiments of reproducing the present climate using the non-hydrostatic regional climate model. SOLA, 4 , 25-28, https://doi.org/10.2151/sola.2008-007.

Sogawa, N., and M. Suzuki, 2008: Long term nonstationarities of some fixed period precipitations over Japanese Islands in the 20th century and their influence upon the estimated values of the T-year return period precipitations (in Japanese with English abstract). J. Natural Disaster Sci., 26, 355-365.

Takara, K., and T. Takasao, 1988: Criteria for evaluating probability distribution models in hydrologic frequency analysis (in Japanese with English abstract). Doboku Gakkai Ronbunshu, 393, 151-160, https://doi.org/10.2208/jscej.1988.393_151.

Takemura, K., Y. Kubo, and S. Maeda, 2017: Relation between a Rossby wave-breaking event and enhanced convective activities in August 2016. SOLA, 13, 120-124, https://doi.org/ 10.2151/sola.2017-022.

Tebaldi, C., K. Hayhoe, J. M. Arblaster, and G. E. Meehl, 2006: Going to the extremes: An intercomparison of modelsimulated historical and future changes in extreme events. Climatic Change, 79, 185-211, https://doi.org/10.1007/s10584006-9051-4.

Trenberth, K. E., 2011: Changes in precipitation with climate change. Climate Res., 47, 123-138, https://doi.org/10.3354/ cr00953.

von Storch, H., and F. W. Zwiers, 1999: Statistical Analysis in Climate Research. Cambridge University Press, 483 pp.

Wehner, M. F., 2004: Predicted twenty-first-century changes in seasonal extreme precipitation events in the Parallel Climate Model. J. Climate, 17, 4281-4290, https://doi.org/10.1175/ JCLI3197.1.

Xie, S.-P., and Coauthors, 2015: Towards predictive understanding of regional climate change. Nat. Climate Change, 5, 921-930, https://doi.org/10.1038/nclimate2689.

Yamada, T. J., M. A. Farukh, T. Fukushima, M. Inatsu, T. Sato, Y. N. Pokhrel, and T. Oki, 2014: Extreme precipitation intensity in future climates associated with the ClausiusClapeyron-like relationship. Hydrol. Res. Lett., 8, 108-113, https://doi.org/10.3178/hrl.8.108.

Yip, S., C. A. T. Ferro, D. B. Stephenson, and E. Hawkins, 2011: A simple, coherent framework for partitioning uncertainty in climate predictions. J. Climate, 24, 4634-4643, https://doi.org/ 10.1175/2011JCLI4085.1.

Yoshida, K., M. Sugi, R. Mizuta, H. Murakami, and M. Ishii, 2017: Future changes in tropical cyclone activity in high-resolution large ensemble simulations. Geophys. Res. Lett., 44, 99109917, https://doi.org/10.1002/2017GL075058.

Yue, S., and M. Hashino, 2007: Probability distribution of annual, seasonal and monthly precipitation in Japan. Hydrol. Sci. J., 52, 863-877, https://doi.org/10.1623/hysj.52.5.863. 